\title{
INITIAL GLOTTALIZATION AND FINAL DEVOICING IN POLISH ENGLISH
}

\author{
GEOFFREY SCHWARTZ \\ UAM Poznań
}

\begin{abstract}
This paper presents an acoustic study of the speech of Polish leaners of English. The experiment was concerned with English sequences of the type George often, in which a word-final voiced obstruent was followed by a word-initial vowel. Acoustic measurements indicated the degree to which learners transferred Polish-style glottalization on word-initial vowels into their L2 speech. Temporal parameters associated with the production of final voiced obstruents in English were also measured. The results suggest that initial glottalization may be a contributing factor to final devoicing errors. Adopting English-style 'liaison' in which the final obstruent is syllabified as an onset to the initial vowel is argued to be a useful goal for English pronunciation syllabi. The implications of the experiment for phonological theory are also discussed. A hierarchical view of syllabic structures proposed in the Onset Prominence environment allows for the non-arbitrary representation of word boundaries in both Polish and English.
\end{abstract}

\section{Introduction}

In the development of English pronunciation teaching materials, issues of phonological representation may lead to conflicting strategies with regard to given aspects of the target language phonology. For example, the ship-sheep contrast may be described in terms of a number of different phonological features, including [tense], [ATR] and [long]. This variety of description can confuse learners and teachers alike, and lead to undesirable results. I have heard many learners, presumably on the basis of the descriptions of "long /i:/", produce unnaturally long vowels in words such as sheep. In this connection, it may be worthwhile to go back and re-evaluate traditional phonological descriptions of target-language segments with the goal of increasing teacher and learner awareness of their most salient properties. For the sheep-ship contrast, studies such as Kaźmierski (2007) have suggested that the dynamic properties of English vowels (Strange 1989), in particular diphthongization, are worth focusing on. With regard to the nasal $/ \mathrm{y} /$, Schwartz (2011) found that learners' tendency for stop insertion in words such as singer may be alleviated be revising the traditional 'velar' description of the sound. Briefly stated, it some cases it may be worth re-evaluating our descriptions and representations of the most difficult aspects of L2 speech.

The English voice contrast in word-final position may represent another candidate for this kind of representational refinement. Due to aerodynamic factors, final voiced obstruents present a phonetic challenge for foreign leaners in the acquisition of English phonology. Final devoicing (FD), a well-known feature of the phonology of many 
languages, is one of the more frequently cited contributors to a Polish accent (e.g. Gonet and Pietron 2004) in English. Its avoidance is a priority in ESL pronunciation teaching. Final devoicing frequently occurs in the native language as well, but without the neutralization of the laryngeal contrast, the preservation of which may be attributed to two phonetic parameters. The first, the relative duration of the final consonant and its preceding vowel, is an example of well-documented phonetic universal (Chen 1970, Maddieson 1997) that English has chosen to exaggerate (Port and Dalby 1982). Vowels are clipped before unvoiced consonants, which are longer in duration. Voiced consonants are shorter in duration, and the vowels preceding them are longer.

English speakers often employ an additional strategy in overcoming the phonetic challenge of final voiced obstruents. They have a tendency to 'liaise' the final consonants with the beginning of the following word, especially if that word begins with a vowel. In other words, phrases such as hold on and tries it are generally pronounced by native speakers as if they were written whole Don or try zit. As a result of this process, the final obstruent in question loses its 'final' status, and is no longer in the environment for FD to apply. Liaison is described in most teaching materials I have seen, but it is usually relegated to descriptions of 'connected speech phenomena' that do not comprise the main focus of textbooks. In the context of Polish instruction in English pronunciation, final devoicing is emphasized as an area of L1 interference that must be overcome. While the durational properties discussed above do get some mention, liaison is rarely mentioned in connection with final voicing.

With regard to liaison, the Polish and English phonological systems are diametrically opposed. Liaison in English results in a rearrangement of syllabic affiliation - the final consonant becomes an onset to the first syllable of the following word. This process may be motivated by an apparent universal preference for syllables with consonantal onsets. In Polish, resyllabification across word boundaries is impossible (Rubach and Booij 1990). The preference for consonantal onsets is satisfied by means of an alternative strategy: glottal stop insertion. Glottal stops may be claimed to fill an 'empty onset' position to repair a non-optimal syllabic structure. However, glottalization may have further prosodic implications, underlying the 'initial' status of vowels at the start of a word, and reinforcing the 'finality' of the preceding consonant, thereby preserving the context for final devoicing. As a consequence, although FD in Polish English is generally described as a simple segmental error, it may have far-reaching phonological consequences. In particular, the study presented here touches on the question of how Polish and English differ with respect to the representation of word boundaries.

These phonological considerations suggest that in Polish English we might look for a correlation between FD and glottal stop insertion - we would predict that speakers who glottalize initial vowels in English should be more likely to devoice final obstruents. A preliminary study (Rejniak 2011) of a corpus of Polish English speech suggests that such a correlation indeed exists. An impressionistic analysis found that the number of devoicing errors rose in accordance with the number of glottal stop insertions. This paper will present the results of an acoustic study of Polish English speech that seeks to investigate this correlation. After some discussion of the phonetic parameters under study in Section 2, the experimental procedure and results are described in Section 3. Section 4 offers a new phonological perspective on these issues, and Section 5 concludes. 


\section{Phonetic aspects of (de)voicing and glottalization}

The phenomenon of final obstruent devoicing is a well-known feature of a large number of languages, and is particularly prevalent in the languages of Europe, including most members of the Slavic family, German, Dutch, and Catalan. It may be seen as a necessary aerodynamic consequence of the final portion of a sequence of speech sounds, during which airflow through the vocal tract has a natural tendency to diminish. Since airflow through the glottis is what makes voicing possible, the decrease of airflow is expected to be accompanied by a lack of vocal fold vibration. As a result of this challenge, languages that maintain laryngeal contrasts in final position often employ additional strategies to produce a distinction. For example, in French one may often observe a short vowel after the release of a final voiced consonant, suggesting that extra effort has been made to maintain the airflow required for voicing. Vowel intrusion may be seen as a process that is parallel with the classic liaisons in phrases like les hommes [le zom] 'the men'. The result is a syllable-initial consonant during which it is easier to maintain voicing.

Before pauses and consonant-initial words, final obstruent devoicing often occurs in English, particularly in the case of fricatives. However, the "voice" contrast is preserved through exploitation of a known phonetic universal (Maddieson 1997): vowels are longer before voiced consonants than before voiceless ones. The magnitude of this difference is much greater in English than in other languages (Chen 1970), so we may assume that English has exaggerated this phonetic property in order to keep the laryngeal contrast readily perceptible in the face of weak or absent vocal fold vibration in final consonants. Alongside this difference in vowel duration, we find that consonants too are also marked by universal voice-related durational properties: voiced consonants are shorter than voiceless ones. English may be claimed to exaggerate this property as well. While this fact is widely noted with regard to aspirated initial stops, the extended duration of final voiceless consonants in English, a feature described in experimental phonetic studies (e.g. Port and Dalby 1982), is not a priority of most English pronunciation materials.

While Polish is if course known for final obstruent devoicing, the Southern and Western regions of the country have been observed to exhibit voicing between vowels across word boundaries. This process, known as Poznań-Cracow voicing has been found to neutralize the laryngeal contrast in favor of the voiced variant, so the phrase brat Ewy 'Eve's brother' is pronounced as [bradevi]. This voicing process may conceivably be interpreted as a form of 'liaison' that blocks the insertion of glottal stops, which are voiceless. Our acoustic study includes four speakers from the Wielkopolska region where this voicing process is attested.

The term glottalization may be associated with two different phonological phenomena. In the study of English accents and pronunciation, the terms glottalization and glottaling are frequently associated with a process by which $/ \mathrm{t} / \mathrm{is}$ replaced by glottal stops. As an allophone of / $t$, the glottal stop is commonly assumed to be the result of a lenition process in casual speech. By contrast, the glottalization of word-initial vowels serves as a marker to a prosodic boundary. It represents a form of strengthening, making the syllable boundary more robust for listeners. Our focus in this paper will be on the glottalization of word-initial vowels. 
In English, initial glottalization has been found to be largely dependent on higher-level prosodic structures. That is, it most frequently appears on word-initial vowels at phrase boundaries, but not within a phrase. For example, in a study based on a corpus of radio announcers' speech, Dilley et al (1996) found that glottalization rates for phrase-initial vowels were around $60 \%$, while word-initial vowels within phrases were glottalized around $20 \%$ of the time. In Polish, glottalization appears to be a syllable-level process, motivated by the preference for consonantal onsets. The process has been reported to be present on word-initial vowels (Dukiewicz and Sawicka 1995, Gussmann 2007) without reference to phrase-level structures. It may even be found within words on morphemeinitial vowels: nauka 'science' may surface as [na 'uka]. As a result, although there is little published data that is comparable to the studies describing English, it is reasonable to assume that glottalization in Polish is more widespread than in English, which largely limits the process to phrase-initial position.

One important aspect of glottalization that may be observed in both initial vowels as well as glottalized allophones of $/ \mathrm{t} /$ is phonetic variability. While a canonical glottal stop is characterized by a full closure, this feature often fails to surface in natural speech. This is especially true in the case of intervocalic glottal stops, which may be perceived on the basis of drops in pitch and small irregularities in the periodicity of the vocal wave. The various irregularities have been described for English in Redi and Shattuck-Hufnagel (2001) and Ashby and Przedlacka (2011). As it turns out, in the study described in this paper it will be possible to describe glottalization in terms of the duration of full closure. This is due to two factors: (1) we will not analyze glottalization at vowel hiatus where full closure is not often achieved, and (2) we will analyze second language speech, in which casual speech processes such as the reduction of glottal closure should be relatively infrequent.

\section{Experimental method}

This section describes an acoustic study of Polish English speech. Our experiment will address the following questions.

1. To what extent do Polish speakers transfer initial glottalization into their English speech?

2. What effect does initial glottalization have on the realization of final voiced obstruents in Polish English?

3. Do speakers from dialect regions associated with Poznan-Cracow voicing show different behavior in their L2 with regard to these parameters?

\subsection{Subjects and Data}

10 first year students of English at the School of English at Adam Mickiewicz University in Poznań, Poland participated in the acoustic study. The students were recorded in a soundproof recording booth. The linguistic materials were comprised of a list of English sentences containing sequences of word-final voiced obstruent(s) + wordinitial vowel, such as George often, today's express train, Fred's aunt. The data set 
included 20 such sequences, as well as additional sentences to control for list reading effects. The sentence list was read twice by each subject, producing 40 sequences for analysis per speaker*10 speakers $=400$ tokens for analysis. A native speaker of American English also read the sentence list.

\subsection{Acoustic measurements}

The acoustic measurements were performed by hand using the Praat program. The following measurements and calculations were made.

1. Duration in milliseconds of vowel preceding final consonant (VD)

2. Duration in milliseconds of final consonant (CD). For stops and affricates this measurement combined both closure and noise bursts/frication.

3. V/C ratio: (VD/CD)

4. Duration in milliseconds of glottal closure (GC) from end of consonant noise to onset of voicing on the vowel.

5. Duration in seconds of each sentence (RATE), allowing for the control of speech rate.

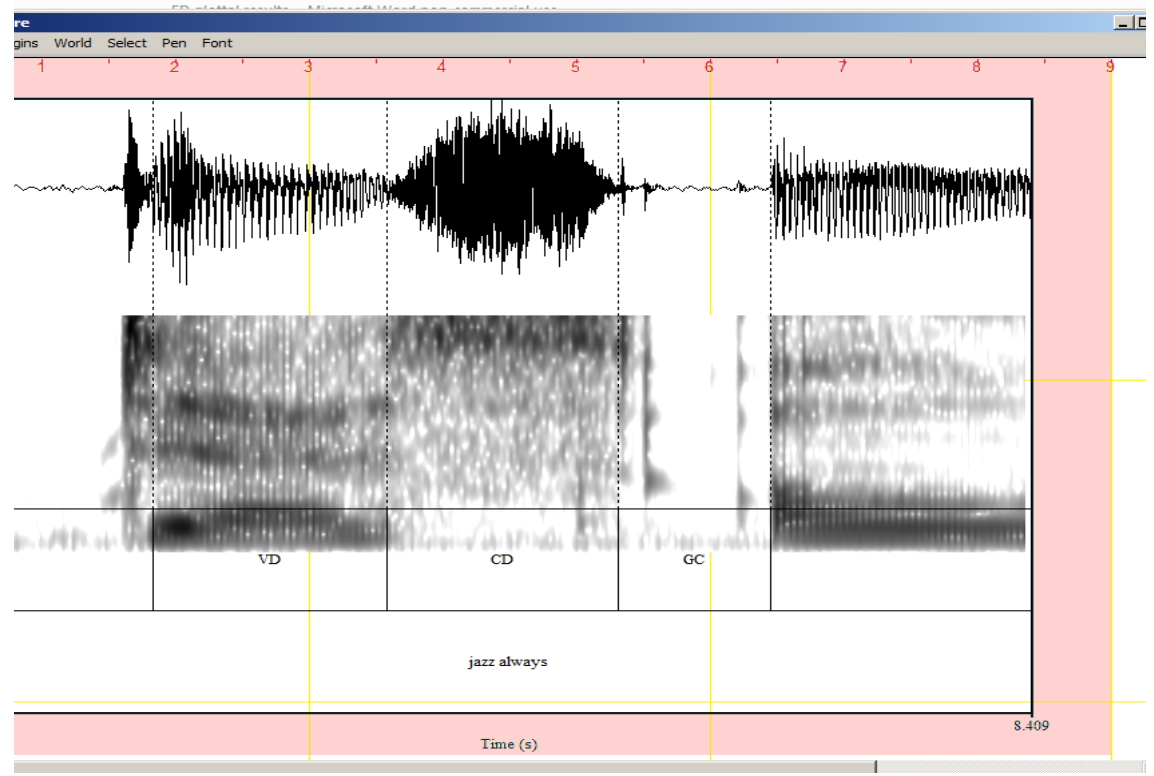

Figure 1 - Illustration of acoustic measurements for the sequence jazz, always. VD represents vowel duration $(142 \mathrm{~ms})$, CD consonant duration $(140 \mathrm{~ms})$, and GC indicates glottal closure duration (92 ms).

Figure 1 presents an illustration of the acoustic measurements on the sequence jazz always. The following measurements (Rate is not included in this illustration) were made on this token: $\mathrm{VD}=142 \mathrm{~ms}, \mathrm{CD}=140 \mathrm{~ms}, \mathrm{~V} / \mathrm{C}=1.01, \mathrm{GC}=92 \mathrm{~ms}$. 
The GC measurement was complicated somewhat by irregularities in the vocal wave associated with glottalization (Redi and Shattuck-Hufnagel 2001, Ashby and Przedlacka 2011). Figure 2 shows an example of this difficulty in the obstruent-vowel sequence in the phrase George often. Note that at vowel onset there are two pulses of highly laryngealized voicing. Since this type of irregularity is associated with the perception of glottal stops, in such cases the GC measurement was extended to the onset of modal voicing, characterized by a regular periodic pattern in the waveform. The glottal pulse trackers in Praat were of assistance in identifying the onset of modal voicing.

For the purposes of the research questions, the $\mathrm{V} / \mathrm{C}$ ratio and the $\mathrm{GC}$ measurements allow us to characterize the degree of final devoicing and the extent of initial glottalization. A higher $\mathrm{V} / \mathrm{C}$ ratio is associated with error-free final voiced obstruents. A shorter GC measurement indicates that the consonant and vowel have been liaised, while longer glottal closure is of course associated with glottal stops.

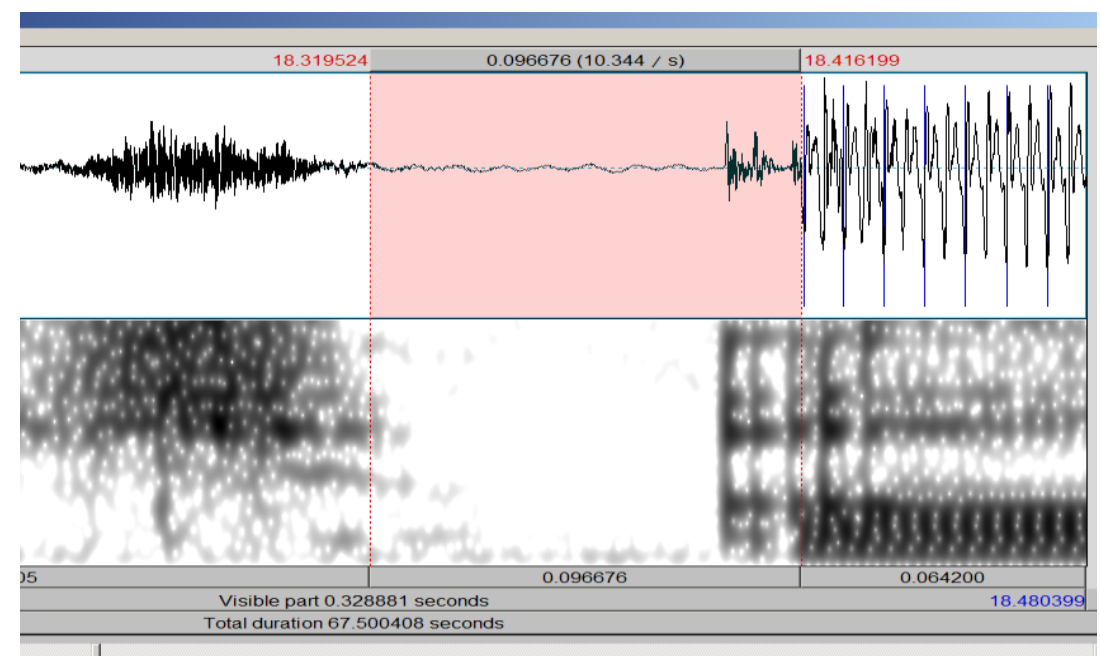

Figure 2 - Glottal closure duration measurement in George often. Measurement includes two cycles of highly laryngealized glottal pulsing.

\subsection{Results - Individual data}

The mean results for each individual speaker are provided in Table 1. Three speakers had Rate measurements that fell outside of the standard deviation for the entire group, indicated by shading in the appropriate cell. These speakers were excluded from the group analysis. Note that the GC measurements for the non-native subjects exhibited a wide range, from just under 9 to over 100 milliseconds. The native speaker inserted showed measurable glottal closure in just one of 40 tokens, for an average GC measurement of less than 2 milliseconds. The native speaker's V/C ratio was 2.9 , while that of the non-natives ranged from 1.33 to 2.72 


\begin{tabular}{|l|l|l|l|l|l|}
\hline Speaker & & VD & GC & V/C & RATE \\
\hline Native & 148.1 & 57.9 & 1.33 & 2.90 & 1.96 \\
\hline pm1 & 118.5 & 102.1 & 85.9 & 1.33 & 2.26 \\
\hline kp1 & 116.2 & 68.7 & 30.06 & 2.07 & 2.07 \\
\hline kp2 & 114.4 & 79.1 & 58.8 & 1.55 & 2.06 \\
\hline kp3 & 169.3 & 76.6 & 57.05 & 2.72 & 2.62 \\
\hline pm2 & 164.0 & 88.9 & 103.5 & 2.05 & 2.74 \\
\hline wm1 & 120.7 & 98.8 & 59.4 & 1.32 & 2.23 \\
\hline wlkp1 & 157.4 & 94.36 & 60.6 & 1.77 & 2.67 \\
\hline wlkp2 & 138.2 & 94.8 & 67.2 & 1.63 & 2.55 \\
\hline wlkp3 & 145.6 & 75.28 & 8.9 & 2.02 & 2.55 \\
\hline wlkp4 & 144.4 & 99 & 26.1 & 1.65 & 2.41 \\
\hline
\end{tabular}

Table 1 - Mean results for each individual speaker. Shaded cells denote speakers whose Rate average fell outside of the group standard deviation. These speakers were excluded from the group analysis.

\subsection{Group Data and interaction of GC with voicing parameters}

To investigate the possible effects of GC duration on the voicing parameters, each individual measurement was placed into one of three categories depending on the value of the GC measurement. Type 1 was comprised of GC measurements of less than $40 \mathrm{~ms}$, and may be described partially or completely liaised. Type 2 included GC measurements between 40-79 milliseconds, while Type 3 covered glottal closures of over $80 \mathrm{~ms}$. From the 8 speakers analyzed in the group data, there were 112 tokens of type 1,119 tokens of type 2 , and 89 tokens of type 3 .

\begin{tabular}{|l|l|l|l|}
\hline Parameter & $\begin{array}{l}\text { Type 1; } \\
0-39 \mathrm{~ms} ; \mathrm{n}=112\end{array}$ & $\begin{array}{l}\text { Type 2; } \\
40-79 \mathrm{~ms} ; \mathrm{n}=119\end{array}$ & $\begin{array}{l}\text { Type 3; } \\
>80 \mathrm{~ms} ; \mathrm{n}=89\end{array}$ \\
\hline V/C & 2.25 & 1.65 & 1.42 \\
\hline VD & 142.3 & 134.7 & 131.7 \\
\hline CD & 71.7 & 88.9 & 104.9 \\
\hline
\end{tabular}

Table 2 - Voicing parameter means sorted according to three types of glottal closure duration.

The mean results of the measurements sorted according to glottal closure duration are presented in Table 2. A one-way analysis of variance (ANOVA) was performed to 
establish the effects of Glottal Closure token type on the voicing parameters. Significant effects $(\mathrm{p}<0.01)$ were found for both V/C ration and Consonant Duration. No significant effect was found for Vowel Duration ( $\mathrm{p}=0.17$ ). Post-hoc Tukey tests were performed on the pairs of means. For V/C ratio and Consonant Duration all pairwise comparisons were significant. For Vowel Duration, Type 1 and Type 3 were significantly different, while the other pairwise comparisons were insignificant

\subsection{Effects of dialect}

Our study may also raise the question of whether intervocalic voicing across word boundaries, a feature associated with certain dialect regions, may be found in these speakers' L2 English, and if so, what if any effect does it have on the parameters of final voicing. Of the 10 subjects recorded for this experiment, 4 of them reported that they were raised in Wielkopolska, an area of Poland associated with intervocalic voicing. The results of the acoustic study were thus sorted according to dialect background to investigate any possible effects on the parameters under study. The dialect results are given in Table 3, which shows the mean values of the voicing and glottal closure parameters, as well as the percentage of Type 1 (liaised) tokens. A one-way ANOVA revealed a significant effect of dialect on Glottal Closure duration, which was shorter for the Wielkopolska speakers. In addition a chi-square test on the percentage of liaised (Type 1) tokens was significant: Wielkopolska speakers were more likely than the others to produced 'liaised' sequences. No significant effect of dialect was found for the voicing parameters

\begin{tabular}{|l|l|l|l|l|l|}
\hline Dialect & VD & CD & GC & V/C & \% Type 1 \\
\hline Wielkopolska & 139.5 & 84.1 & 40.9 & 1.74 & 47.5 \\
\hline Other & 133.8 & 90.2 & 67.4 & 1.77 & 29.5 \\
\hline
\end{tabular}

Table 3 - Acoustic measurements sorted for dialect background.

\subsection{Discussion}

The results of the acoustic study support the hypothesis that glottalization of initial vowels may contribute to final obstruent devoicing in the speech of Polish leaners of English. In this connection it is interesting to observe the results obtained from the native speaker, who showed almost across-the-board liaison, as well as the highest V/C ratio of all the recorded subjects. Table 4 shows a comparison of the native speaker with group mean values of the non-native. For the Polish speakers, the average glottal closure duration of $60.8 \mathrm{~ms}$ fell within the Type 2 range, while the V/C ratio was 1.76 , notably lower than that of the native speaker. Thus, it is reasonable to claim that liaison is a clear 
aspect of native-like speech that contributes to the production of 'final' voiced obstruents.

\begin{tabular}{|l|l|l|l|}
\hline & V/C & GC & \% Type 1 \\
\hline Native control & 2.9 & 1.33 & 97.5 \\
\hline Non-native & 1.76 & 60.8 & 38 \\
\hline
\end{tabular}

Table 4 - Comparison of native speaker control with group data for Polish learners.

When the analyzed tokens were divided into three types of the basis of Glottal Closure duration, a clear effect was found for token type on both the V/C ratio and the Consonant Duration. Importantly, the effect of token type on Vowel Duration was not significant. This fact suggests that we may rule out speech rate as a factor in the group results. While one may be inclined to attribute initial glottalization to the fact that the subjects were speaking more slowly in a foreign language, rate effects should have been equivalent for each of the parameters involved. This was not the case - only the final consonant was affected.

The effect of Glottal Closure duration on the duration of final consonants may be attributable to a process of final lengthening by which segments are lengthened at the end of prosodic constituents (Beckman and Edwards 1990). Final devoicing and final lengthening should be expected to co-occur. The longer a consonant is, the more likely it is to be unvoiced, since more effort is required to sustain the glottal airflow required for voicing over the course of a lengthened consonantal constriction. In other words, we are witnessing the manifestation of a phonetic universal by which unvoiced consonants are longer than voiced ones.

When liaison occurs, the context for final lengthening (and final devoicing) is eliminated; the consonant is no longer final. Thus, although final lengthening does occur in English (Beckman and Edwards 1990), the native speaker produced liaised consonants instead of longer final ones that would be more susceptible to devoicing. These results suggest that Polish and English have somewhat different representations of "final" and "initial" positions. We will take up this issue in detail in the following section.

The data from the dialect groups may complicate the picture. The results indicated that speakers from Wielkopolska produced more 'liaised' tokens, but this did not seem to have a significant effect on the durational patterns associated with voicing. That is, more liaison did not necessarily imply less devoicing, at least in terms of the temporal parameters. One possible clue in explaining the discrepancy associated with the Wielkopolska speakers may be found in the behavior of one speaker, who in many instances showed an intrusive vowel before a glottalized initial vowel. For example, in the phrase Today's express train, the speaker produced a short vocoid after the final /z/, and then showed full glottal closure on the initial vowel of express, resulting in a sequence $\left[\mathrm{z}^{2} \mathrm{P} \varepsilon\right]$. Since a full glottal stop is produced, we may not claim that liaison has been acquired. The speaker appears to have adopted a vowel-insertion strategy to produce fully voiced final obstruents, perhaps diminishing the significance of the temporal parameters. 


\section{The phonology of boundaries}

The acoustic study described in this paper reflects a fundamental difference in the phonology of English and Polish with regard to the behavior of speech sounds at word boundaries. Stated briefly, word boundaries in Polish seem to block many common phonological processes that might be expected to accompany the concatenation of two sounds. In English, on the other hand many such processes are common.

For example, Polish morphology shows a number of palatalization processes that turn coronal stops into alveolo-palatal affricates before certain grammatical endings. Thus, the locative of the form $/ \mathrm{kot} /$ ' cat' is / kotce/. The traditional assumption is that it is the frontness of the vowel in the ending that conditions the alternation - the $/ t /$ is said to be 'palatalized'. In a sequence kot jest 'the cat is', one might expect the palatal glide in jest to cause palatalization of the /t/. It does not, so we may assume that the concatenation process that results in the alternation at the morpheme boundary does not apply at the word boundary. Conversely we frequently observe palatalization in an analogous sequence got you in English, which is often pronounced as gotcha.

These facts are connected with the notion of resyllabification across wordboundaries, by which a word-final coda consonant is reinterpreted as the onset to the following syllable. Thus, for English we may make a generalizing statement that a sequence / $\mathrm{t}$ / in a syllable onset results in a post-alveolar affricate. Resyllabification is impossible in Polish (Rubach and Booij 1990), so the /t/ and the /j/ in kot jest must be analyzed as belonging to two separate syllabic constituents. Liaison in English may be interpreted as a form of this type of resyllabification.

The Onset Prominence representational environment (OP; Schwartz 2010) offers a useful set of materials for analyzing the different behavior in Polish and English at word boundaries. OP builds on recent insights into the structural nature of segmental phonology, in particular manner of articulation (Golston and Hulst 1999, Pöchtrager 2006). The basic building block of the OP representational environment, which may be seen as the functional equivalent of a universal CV structure, is given in Figure 3. The tree represents the acoustic signal as a hierarchical structure, from which both segmental representations and prosodic categories such as syllables are derived. Manner is defined by the layers of structure present in the segmental representation. Figure 3 represents a stop-vowel sequence.

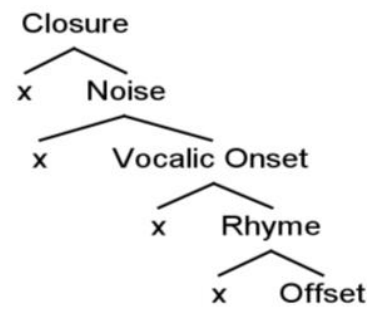

Figure 3 - Basic building block of syllabic structures in the OP environment. 
In the OP environment, syllabic constituents such as the one in Figure 3 are formed from the concatenation of individual segmental structures. Consider Figure 4, in which the representation of the stop / $/ \mathrm{k}$ contains the top two layers of the structure in Figure 3, the /w/ contains the Vocalic Onset node, and the vowel and final / $/ \mathrm{k}$ represent the Rhyme. These structures combine to form the English word quick. Such a sequence, since it proceeds down the hierarchy is predicted to be contained a single syllabic constituent ${ }^{1}$. The basic principle for syllabification is that a tree may be "absorbed" into a higher level structure to its left, so the three structures in Figure 4 may combine into a single constituent.
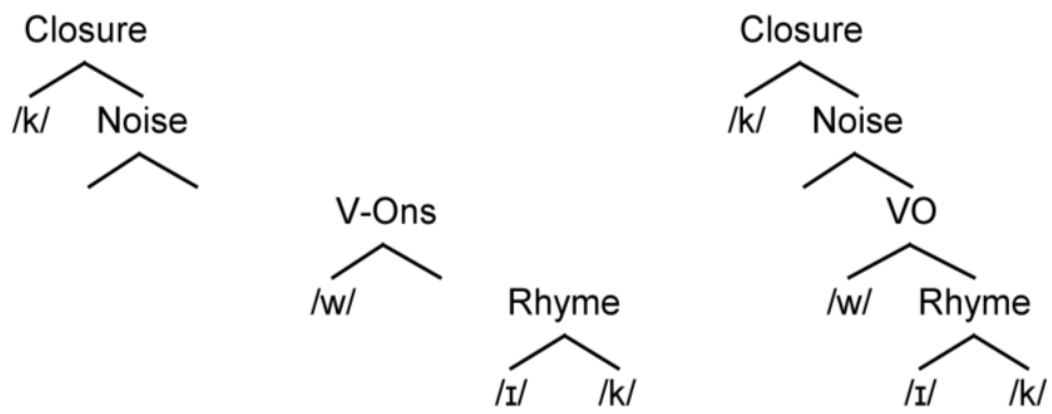

Figure 4 - Syllabification of English quick in the OP environment

For the representation of initial vowels in Polish, we claim that they contain an additional layer of structure, namely the Closure node associated with stops. Since it is not a lower-level structure than the preceding consonant, the vowel may not be absorbed into the tree to its left. Resyllabification does not occur, and the "final" status of the consonant is reinforced. This is illustrated in Figure 5, which shows a word-final /d/ followed by an initial /e/ as they would be represented in Polish using OP structures.

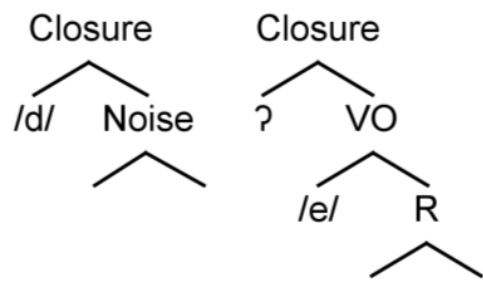

Figure 5 - Sequence of word-final /d/ and word-initial /e/ in Polish. The active Closure node on the vowel blocks the merging of the two trees.

1 The presence of the $/ \mathrm{k} /$ in the rhyme is the result of a submersion process for codas that will not be relevant for the present paper. 
In Figure 6 we see an analogous sequence in English. Note that the English vowel does not contain the extra structure, and the tree on the right may be absorbed into the one on the left, reflecting liaison and resyllabification. The difference between Polish and English is captured in terms of the structural properties of the initial vowel. Initial vowels in Polish are larger structures than they are in English. They might be thought to contain a "built-in" glottal stop, which blocks resyllabification across word boundaries" .

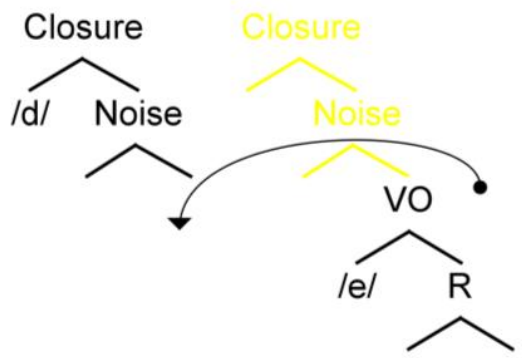

Figure 6 - English sequence of final /d/ and initial /e/ producing liaison.

This representational approach comes with benefits for both phonological theory and comparative descriptions of Polish and English phonology upon which we may base teaching materials. The advantage concerns the representation of phonological boundaries. In phonology, this has been a recurring problem. Symbols (such as + and \#) traditionally used to represent such boundaries are inherently arbitrary in nature (e.g. Scheer 2008). By contrast, in the Onset Prominence environment, such boundaries may be constructed using the structure of segments themselves - they are truly 'phonological' entities. With regard to teaching materials, the value of OP representations lies in the fact that they are hierarchical. Unlike a linear string of segmental symbols, this approach allows for a faithful model of what actually happens in speech.

\section{Final remarks}

This paper has described an acoustic study of the speech of Polish learners of English. The results, as well as the ensuing phonological discussion, suggest the need to establish principled representations of phonological boundaries. Languages appear to show systematic differences in the behavior of word-initial and word-final segments, which manifest themselves in a number of processes found in Second Language speech. The Onset Prominence environment offers a principled explanation of these differences, with benefits for both phonological theory and second language speech acquisition.

2 In the case of kot jest, resyllabification is prevented by the 'promotion' of the structure of the $/ \mathrm{j} /$. 


\section{References}

Ashby, M. \& J. Przedlacka. 2011. The stops that aren’t. Ms. UCL.

Beckman, Mary \& Jan Edwards. 1990. Lengthenings and shortenings and the nature of prosodic constituency. In J. Kingston \& M. Beckman (eds.), Papers in Laboratory Phonology I: 179-200. Cambridge, UK: Cambridge University Press.

Chen, Matthew. 1970. Vowel length variation as a function of the voicing of the consonant environment. Phonetica 22: 129-159.

Dilley, L., Shattuck-Hufnagel, S., and Ostendorf, M. 1996. Glottalization of word-initial vowels as a function of prosodic structure. Journal of Phonetics 24: 423-444.

Dukiewicz, L. and I. Sawicka. 1995. Gramatyka wspótczesnego języka polskiego fonetyka i fonologia. Kraków: Wydawnictwo Instytutu Języka Polskiego PAN.

Golston, C. and H. van der Hulst. 1999. Stricture is structure. In B. Hermans and M. van Oostendorp, (eds.) The Derivational Residue in Phonological Optimality Theory. Amsterdam: John Benjamins: 153-173.

Gonet, W. \& G. Pietroń. 2004. The Polish Tongue in the English Ear. Zeszyty Naukowe PWSZ w Koninie, nr 1/2004 (4), pp. 56-65.

Gussmann, E. 2007. The Phonology of Polish. Oxford: Oxford University Press.

Kaźmierski, K. 2007. Dynamic specification in English vowels - implications for Polish learners. Unpublished BA thesis. UAM Poznań.

Maddieson, I. (1997). Phonetic universals. In Hardcastle, W. and J. Laver (eds). The Handbook of Phonetic Sciences. Cambridge: Blackwell. 619-640.

Pöchtrager, M. 2006. The structure of length. Ph.D. dissertation. University of Vienna.

Port, R. \& J. Dalby. 1982. C/V ratio as a cue for voicing in English. Perception and Psychophysics 2. 141-152.

Redi, L. and S. Shattuck-Hufnagel. 2001. Variation in the realization of glottalization in normal speakers. Journal of Phonetics 29: 407-429.

Rejniak, J. 2011. What is final? Factors affecting devoicing errors in the speech of Polish learners of English. Unpublished BA thesis. UAM Poznań.

Rubach, J. and G. Booij. 1990. Syllable structure assignment in Polish. Phonology 7: 121-158.

Scheer, T. 2008. Why the Prosodic Hierarchy is a diacritic and why the Interface must be Direct. Sounds of Silence: Empty Elements in Syntax and Phonology, edited by Jutta Hartmann, Veronika Hegedüs \& Henk van Riemsdijk, 145-192. Amsterdam: Elsevier.

Schwartz, G. 2010. Auditory representations and the structures of GP 2.0. Acta Linguistica Hungarica 57: 381-397.

Schwartz, G. 2011. Avoiding stop insertion after English angma - a representational solution. In: Dziubalska-Kołaczyk, K.; Wrembel, M.; Kul,M. (eds.). Achievements and perspectives in SLA of speech: New Sounds 2010. Berlin: Peter Lang: 241-250.

Strange, W. 1989. Dynamic specification of coarticulated vowels spoken in sentence context. JASA 85: 2135-2153. 